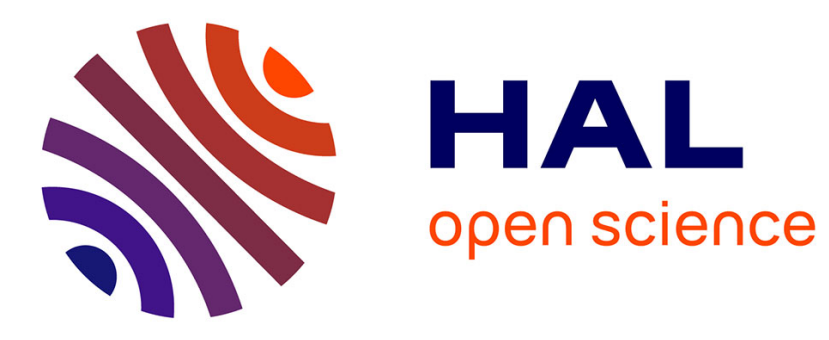

\title{
Size-independent fracture energy of concrete at very early ages by inverse analysis
}

Mohammed Matallah, Mounia Farah, Frédéric Grondin, Ahmed Loukili, Emmanuel Rozière

\section{- To cite this version:}

Mohammed Matallah, Mounia Farah, Frédéric Grondin, Ahmed Loukili, Emmanuel Rozière. Sizeindependent fracture energy of concrete at very early ages by inverse analysis. Engineering Fracture Mechanics, 2013, 109, pp.1-16. 10.1016/j.engfracmech.2013.05.016 . hal-01007309

\section{HAL Id: hal-01007309 \\ https://hal.science/hal-01007309}

Submitted on 11 Mar 2018

HAL is a multi-disciplinary open access archive for the deposit and dissemination of scientific research documents, whether they are published or not. The documents may come from teaching and research institutions in France or abroad, or from public or private research centers.
L'archive ouverte pluridisciplinaire HAL, est destinée au dépôt et à la diffusion de documents scientifiques de niveau recherche, publiés ou non, émanant des établissements d'enseignement et de recherche français ou étrangers, des laboratoires publics ou privés. 


\title{
Size-independent fracture energy of concrete at very early ages by inverse analysis
}

\author{
M. Matallah ${ }^{\mathrm{a}, \mathrm{b}, *}$, M. Farah ${ }^{\mathrm{b}}$, F. Grondin $^{\mathrm{b}}$, A. Loukili $^{\mathrm{b}}$, E. Rozière ${ }^{\mathrm{b}}$ \\ a RiSAM, Université de Tlemcen, BP 230 Tlemcen, Algeria

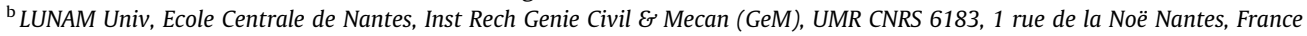

\begin{abstract}
This paper deals with the analysis of fracture characteristics of concrete at very early ages. Experimentally, three-point bending tests are performed on concrete notched beams at very early age (before $24 \mathrm{~h}$ ) to obtain the Load-Crack Mouth Opening Displacement (CMOD) curves. In order to find a trend of the fracture energy evolution, inverse analysis procedure is performed using finite element analysis. A damage softening model is used to describe the softening behaviour and a nonlinear inverse analysis algorithm (Levenberg-Marquardt) is adopted. As the softening damage model used does not take into account boundary effects, only a part of the Load-CMOD curves is fitted. Therefore, a good estimation of the size-independent fracture energy is obtained. The results obtained from the experimental test and the inverse analysis indicate an upward trend of the evolution of the fracture energy and other fracture concrete characteristics.
\end{abstract}

\section{Introduction}

At early ages, cracks can occur in concrete due to the autogenous/drying shrinkage and thermal deformations. As the strength is relatively low, induced tensile stresses may cause premature deterioration which can affect seriously the integrity of the concrete structures. So, the evolution of the early age strength and fracture properties of concrete should be evaluated.

The fracture energy is one of the most important fracture characteristics of concrete. Determination of the evolution of the fracture characteristics at early ages has been already investigated by some authors [1-5]. Based on the three-point bending test or the wedge splitting test, the fracture energy could be evaluated directly from the load-displacement curves according to the RILEM's recommendation, or indirectly, by numerical inverse analysis. When using inverse analysis, experimental results are approximated by repeated numerical simulations. To this end, a function to describe concrete softening is needed. Discrete models (fictitious crack model [6]) or smeared crack models are often used for modelling tensile softening behaviour of concrete. These models require a stress-crack opening relationship. The area under the tensile softening curve described by this relationship determines the specific fracture energy. The softening curve could be approximated by a bilinear [2,4], tetra-linear [7] or multi-linear curves [8].

As defined by the RILEM technical committee, the specific fracture energy measurement is based on the loaddisplacement $(P-\delta)$ curve and expressed as

$$
G_{f}=\frac{1}{b(W-a)} \int P \partial \delta
$$

\footnotetext{
* Corresponding author at: RiSAM, Université de Tlemcen, BP 230 Tlemcen, Algeria. Tel.: +213 556640688.

E-mail address: matallah@mail.univ-tlemcen.dz (M. Matallah).
} 


\section{Nomenclature}

$\begin{array}{ll}\alpha & \text { perturbation } \\ \beta & \text { parameter for the compression damage law } \\ \chi & \text { chi-squared error criterion } \\ \delta & \text { crack opening displacement } \\ \gamma & \text { the biaxiality ratio } \\ \sigma_{i j} & \text { stress tensor components } \\ \tilde{\sigma}_{i j} & \text { effective stress tensor components } \\ \varepsilon^{f r} & \text { fracture strain } \\ \varepsilon_{i j} & \text { strain tensor components } \\ \xi & \text { a hardening-softening variable } \\ a_{1}^{*} & \text { transition length } \\ A_{e l e m} & \text { finite element area } \\ B & \text { parameter of the damage evolution law } \\ C_{i j k l} & \text { elastic stiffness tensor components } \\ E & \text { Young's modulus } \\ f_{t} & \text { tensile strength } \\ G_{F} & \text { size independent fracture energy } \\ G_{f} & \text { RILEM specific fracture energy } \\ g_{f} & \text { local specific fracture energy } \\ h & \text { characteristic length } \\ J & \text { Jacobian matrix } \\ Z & \text { weighted matrix } \\ \sigma & \text { nominal stress } \\ \xi & \text { internal variable } \\ a & \text { initial crack length } \\ b & \text { specimen thickness } \\ d & \text { damage variable } \\ W & \text { specimen width } \\ w & \text { crack opening displacement } \\ & \end{array}$

where $b$ is the specimen thickness, $W$ its width in the crack direction and $a$ the initial notch or crack length. The RILEM energy definition is based on Hillerborg's fictitious crack model. So, the motivation of the RILEM was to provide a constant parameter $G_{f}$ representing the area under the tensile softening curve supposed unique. However, as it is widely agreed, size effect on the RILEM $G_{f}$ exists [9,10]. $G_{f}$ depends not only on the specimens sizes $W$ but also on the crack length $a$ even if $W$ is constant. There is a size/ligament effect on $G_{f}[11-13]$. Eq. (1) gives only an average value where the fracture energy is assumed to be uniform over the crack length.

A number of authors have tried to explain the size/ligament effect on $G_{f}$. Hu and Wittman [14] proposed a $G_{f}$ curve concept where the specific fracture energy is assumed to vary along the crack path. This local specific fracture energy is function of crack length $\left(g_{f}(a)\right)$ and the experimentally determined $G_{f}(a)$

$$
g_{f}(a)=G_{f}(a)-(W-a) \frac{d G_{f}(a)}{d a}
$$

where $G_{f}(a)$ represents the crack length-dependent fracture energy or the specific fracture energy (measured by testing concrete specimens of fixed size but different crack length). A bilinear distribution of the local fracture energy along the crack path is therefore proposed. Duan et al. $[15,12,10]$ proposed also a bilinear fracture energy distribution where $G_{f}$ is function of the specimen width (Fig. 1)

$$
g_{f}= \begin{cases}G_{F} & W-a>a_{1}^{*} \\ g_{0}+\frac{W-a}{a_{1}^{*}}\left(G_{F}-g_{0}\right) & W-a \leqslant a_{1}^{*}\end{cases}
$$

When performing inverse analysis, the $\sigma-d w$ curve (representing the fracture energy) is searched by fitting P- $\delta$ and/or P-CMOD curves. However, due to boundary effects, the $\sigma-d w$ relation in the FPZ (Fracture Process Zone) varies along the crack because the $h_{F P Z}$ (the Fracture Process Zone height) decreases when the crack approaches the back boundary. Inverse analysis obtained without considering boundary effect, implies a constant $\sigma-d w$ relation along the crack path. If the inverse analysis is performed with a model that does not take into account boundaries effects, the solution we proposed is to fit only a part of the P- $\delta$ (or P-CMOD) curves where the distribution of the local fracture energy is supposed uniform. In this region (the inner zone), a good estimation of the size-independent fracture energy $\left(G_{F}\right)$ could be obtained. 


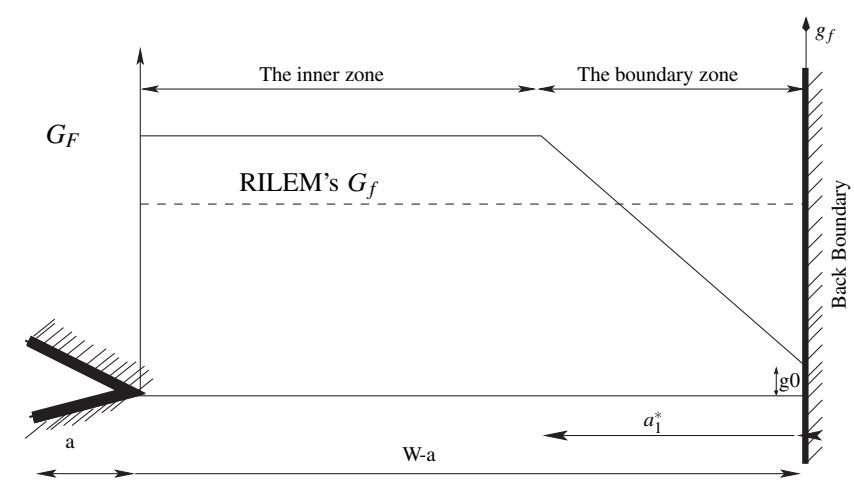

Fig. 1. Bilinear fracture energy distribution [10].

The objective of the present study is to contribute to the identification of the fracture characteristics of concrete at very early ages (especially the evolution of the fracture energy) using inverse analysis. Experimentally, three-point bending tests are performed on rectangular notched beams specimens at ages between $12 \mathrm{~h}$ and $24 \mathrm{~h}$. The Load-CMOD curves are obtained.

In order to estimate the size-independent fracture energy, a damage based model is used to represent the softening behaviour of concrete. The stress-crack opening curve is implicitly taken into account through the smeared softening damage curve (stress-strain relationship). A fracture energy regularization is applied to the model in order to avoid spurious mesh sensitivity. Therefore the energy dissipated due to fracture per unit length (or unit width) described by the stressstrain curves is constant. As the softening behaviour is nonlinear, the Levenberg-Marquardt $[12,13]$ algorithm is used to perform inverse analysis. Only a part of the Load-CMOD curves is fitted in order to estimate the size-independent fracture energy.

\section{Modelling basis}

\subsection{Isotropic damage based model}

As it has been outlined before, the RILEM motivation was to provide a fracture characteristic (the fracture energy) to fictitious crack models [6] which represents the area under the tensile softening curve $(\sigma-d w)$. When using damage models, the stress-crack opening softening curve is implicitly described by the softening damage curve. The tensile softening relation is taken into account through a damage variable which characterises the fracture process. The fracture zone is represented by a damage zone and the material behaviour in the fracture process zone is characterised in a smeared manner.

In the crack band theory, instead of treating cracks as lines as in fictitious crack models, Bazant and Oh [16] consider that the fracture zone has a certain width $h$ over which micro-cracks are uniformly distributed (smeared over a bandwidth). The band width $h$ is regarded as a material parameter. It is required in order to avoid spurious mesh sensitivity and achieve objectivity. The energy dissipation due to fracture per unit length (or unit width) is therefore a constant and is given by

$$
G_{f}=\int_{0}^{\infty} \sigma d \delta=h \int_{0}^{\infty} \sigma d \varepsilon^{f r}
$$

where $\delta$ is the crack opening displacement and $\varepsilon^{\text {fr }}$ the fracture strain. According to this theory, the material behaviour in the fracture process zone is characterised in a smeared manner through a strain-softening constitutive relation. In a damage model, a damage variable characterises the fracture process in a smeared manner and as in the crack band theory, the dissipation must be governed by the fracture energy.

If we consider the original version of the damage model developed in $[17,18]$, the stress-effective stress relationship is defined along a finite set of directions of unit vectors $n$ at each material point

$$
\sigma=(1-d(n)) n_{i} \tilde{\sigma}_{i j} n_{j}
$$

where $d(n)$ is a scalar quantity defining the damage effect and $\tilde{\sigma}_{i j}$ the effective stress tensor components. The evolution of damage is controlled by a loading surface $f$

$$
f(n)=n \tilde{\varepsilon} n-\varepsilon_{d 0}-\xi(n)
$$

$\xi$ is a hardening-softening variable and $\varepsilon_{d 0}$ represents a strain threshold (i.e. the threshold triggering damage).

In we consider the isotropic version of this model (i.e. $\forall n d(n)=d$ ), the damage surface $d(n)$ is approximated by a sphere and the stress-strain relationship reads $[17,18]$ 


$$
\sigma_{i j}=(1-d) C_{i j k l}^{0} \varepsilon_{k l}=(1-d) \tilde{\sigma}_{i j}
$$

where $C_{i j k l}^{0}$ are the components of the initial stiffness tensor.

For the isotropic version, the loading surface is written in terms of the equivalent strain $\tilde{\varepsilon}$ and reads [19]

$$
f=\tilde{\varepsilon}-\varepsilon_{d 0}-\xi
$$

The equivalent strain is computed using the positive eigenvalues of the strain tensor

$$
\tilde{\varepsilon}=\sqrt{\left\langle\varepsilon_{1}\right\rangle_{+}^{2}+\left\langle\varepsilon_{2}\right\rangle_{+}^{2}+\left\langle\varepsilon_{3}\right\rangle_{+}^{2}}
$$

If the damage is isotropic, the evolution of the damage surface is defined by [18]

IF $f=0$ and $\mathrm{d} \tilde{\varepsilon}>0$

$$
\text { Then }\left\{\begin{array}{c}
\mathrm{d} d=\left[\frac{\varepsilon_{d 0}(1+B \tilde{\varepsilon})}{\tilde{\varepsilon}^{2}}\right] \exp \left(-B\left(\tilde{\varepsilon}-\varepsilon_{d 0}\right)\right) \mathrm{d} \tilde{\varepsilon} \\
\mathrm{d} \xi=\mathrm{d} \tilde{\varepsilon}
\end{array}\right.
$$

ELSE; $\mathrm{d} d=0, \mathrm{~d} \xi=0$

The integrated damage evolution law reads [19]

$$
d=1-\frac{\varepsilon_{d 0}}{\tilde{\varepsilon}} \exp \left(B\left(\varepsilon_{d 0}-\tilde{\varepsilon}\right)\right), \quad \dot{d}>0
$$

where $B$ is a parameter which controls the slope of the softening curve defined by the exponential expression.

The damage evolution law proposed above is valid for tension. Under compressive loading, the damage evolution law is directly deduced from the tensile damage

$$
d_{c}=d^{\beta}
$$

The parameter $\beta$ is adjusted to obtain an adequate material response under compressive loading. The complete stressstrain law for the isotropic version of this model reads [19]

$$
\sigma_{i j}=(1-d)\left\langle\tilde{\sigma}_{i j}\right\rangle^{+}+\left(1-d_{c}\right)\left\langle\tilde{\sigma}_{i j}\right\rangle^{-}
$$

where $\left\langle\tilde{\sigma}_{i j}\right\rangle^{+}$and $\left\langle\tilde{\sigma}_{i j}\right\rangle^{-}$are the positive and the negative parts of the effective stress tensor components. Fig. 2 shows a typical uniaxial tension-compression response of the model corresponding to a standard concrete with the following parameters $\left(E=30 \mathrm{GPa}, f_{t}=3 \mathrm{MPa}, \beta=12, B=1 \mathrm{e} 4, \varepsilon_{d 0}=f_{t} / E\right)$.

\subsection{Energetic regularization for one dimensional analysis}

Under tensile loading, the softening relationship is driven by the damage exponential law. When fracture progresses, this leads to a high localisation in a narrow zone of the discretized structures. Dissipation is therefore vanishing in elements with reduced mesh density. The tensile softening behaviour must be changed such we impose the same energy dissipation whatever the element size

$$
\frac{G_{f}}{h}=\int_{0}^{\infty}((1-d) E \varepsilon) d \varepsilon
$$

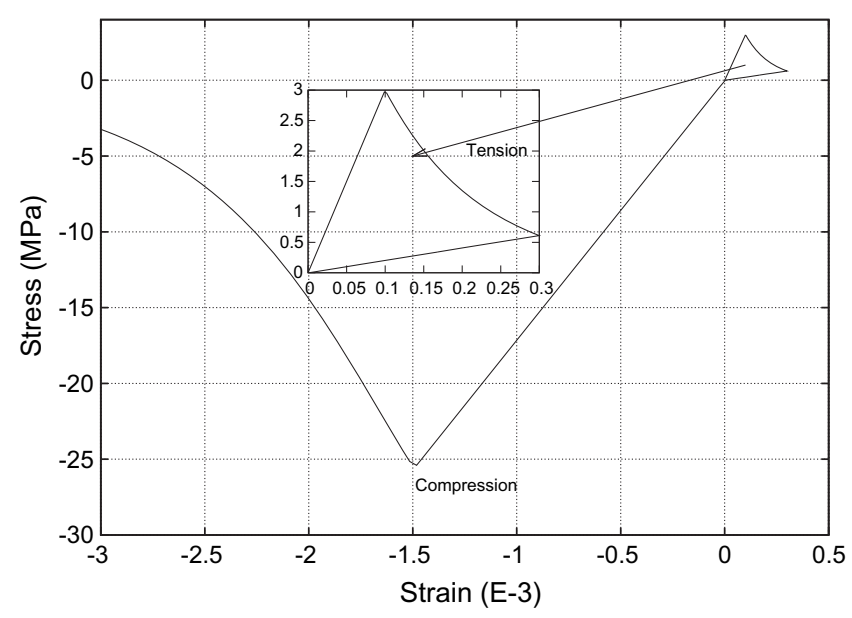

Fig. 2. Uniaxial tension-compression response. 
where $h$ is the characteristic length which should be related to the width of the fracture process zone, i.e. the region where damage is developing. It should be measured in the direction normal to the crack plane. In this study $h=\sqrt{A_{\text {elem }}}$ is adopted where $A_{\text {elem }}$ is the finite element area. The local energy in each element $g_{f}^{\text {elem }}$ is assumed to be distributed uniformly over an element $G_{f}^{\text {elem }}=h * g_{f}^{\text {elem }}$. This implies that micro-cracks are assumed to be uniformly distributed over a finite element as in the crack band theory [16].

After combining Eqs. (13) and (14), the fracture energy is given by:

$$
\frac{G_{f}}{h}=\int_{0}^{\varepsilon_{d 0}}(E \varepsilon) d \varepsilon+\int_{\varepsilon_{d 0}}^{\infty}\left(\frac{\varepsilon_{d 0}}{\varepsilon} \exp \left[B\left(\varepsilon_{d 0}-\varepsilon\right)\right]\right) E \varepsilon d \varepsilon
$$

The first part of the fracture energy corresponds to the elastic contribution $(d=0)$. After integration, Eq. (15) gives

$$
\frac{G_{f}}{h}=\frac{f_{t} \varepsilon_{d 0}}{2}+\frac{f_{t}}{B}
$$

where $f_{t}$ is the tensile strength and $E$ the Young's modulus with $f_{t}=E * \varepsilon_{d 0}$.

This leads to a mesh-independent energy release upon crack propagation. The parameter $B$ which controls the softening curve is given by:

$$
B=\frac{f_{t}}{\frac{f_{f}}{h}-\frac{f_{t} \varepsilon_{00}}{2}}
$$

The proposed fracture energy regularisation is tested on a simple uniaxial tension test [20]. The test consists in a simple bar with length $1 \mathrm{~m}$ and a width $0.1 \mathrm{~m}$ (Fig. 3). The bar is assumed to be fixed on the left. So, the total elongation is therefore equal to the displacement increment applied to the right end in the $x-x$ direction. Fracture is forced in the finite element of width $h$ located at the center of the bar by setting a defect (smaller tensile stress $f_{\text {twe }}$ ). Computations are driven in plane-stress, the material data for concrete are as follows:

$G_{f}=100 \mathrm{~N} / \mathrm{m}, E=30 \mathrm{GPa}$, the tensile strength $f_{t}=3 \mathrm{MPa}$ and the tensile strength for the element with defect $f_{\text {twe }}=1 \mathrm{MPa}$.

The mesh objectivity is shown in Fig. 4 using different discretizations ( $m=11,21,31)$, where $m$ is the number of elements.

\subsection{Energetic regularization for two dimensional analysis}

As it has been outlined in the introduction, the present work deals with an inverse analysis procedure in order to estimate the fracture energy at very early ages. Experimentally, three-point bending tests are performed (Section 4, Fig. 12). In the previous section, the fracture energy (Eq. (16)) was evaluated under uniaxial tension. For a notched beam under three-point bending, the stress state along the crack path is not uniaxial even if the crack is under mode I [21]. The energy dissipated by cracking is affected by the biaxial stress state. In [21], Jirasek and Bauer evaluated the crack band theory under two-dimensional configuration. The biaxial stress effect is analysed for a notched beam under three-point bending test using a simple damage model (with different equivalent strain definitions). A similar analysis is proposed in this section. A notched beam under three-point bending test with the same geometry as that studied experimentally (Fig. 12) is considered. A numerical test is performed using the damage model proposed above using the fracture energy evaluated under uniaxial tension (Eq. (16)). The objective is to evaluate the dissipated energy in the cracking zone and to compare it with the input fracture energy. The following parameter set is considered ( $E=40 \mathrm{GPa}, v=0.2, f_{t}=2.5 \mathrm{MPa}, G_{f}=100 \mathrm{~N} / \mathrm{m}$ ). Computations are driven in planestress. The mesh of the beam is made of 1500 quadrilaterals elements (4 nodes element with linear interpolation) (Fig. 5). In the central part of the beam, the size of the finite element (in the front of the notch) is about $1.6 \mathrm{~mm}$. The parameter $B$ is computed using Eq. (17). Fig. 6 shows the global behaviour of the beam (load vs. deflection). The evolution of the Cartesian components and the principal components of the stress tensor are shown in Figs. 7 and 8. These evolutions are computed for the first cracked finite-element situated in the front of the notch (gauss point 2). Fig. 9 shows the diagrams of principal stresses versus principal strains. The total amount of the fracture energy is

$$
G_{f}=h *\left(\int_{0}^{\infty} \sigma_{1} d \varepsilon_{1}+\int_{0}^{\infty} \sigma_{2} d \varepsilon_{2}\right)=102.56 \mathrm{~N} / \mathrm{M}
$$

The contribution of the minor principal stress (perpendicular to the beam axis) is about $-2.02 E-2 \approx 0 \mathrm{~N} / \mathrm{m}$. The total amount of the fracture energy dissipated by the model is slightly greater than the fracture energy used to perform the numerical simulation (computed from uniaxial tension). This result is in accordance with results obtained in [21]. When

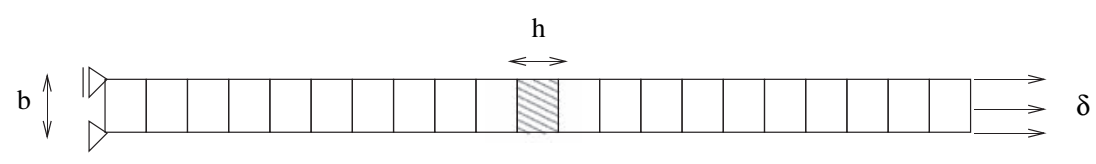

$\mathrm{L}$

Fig. 3. Imperfect bar in pure tension. 


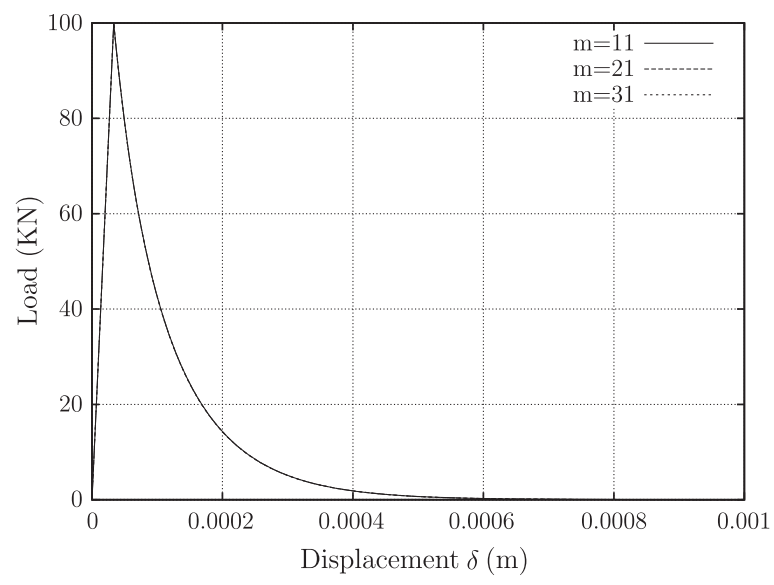

Fig. 4. Load-displacement diagram for $m=11,21,31$.

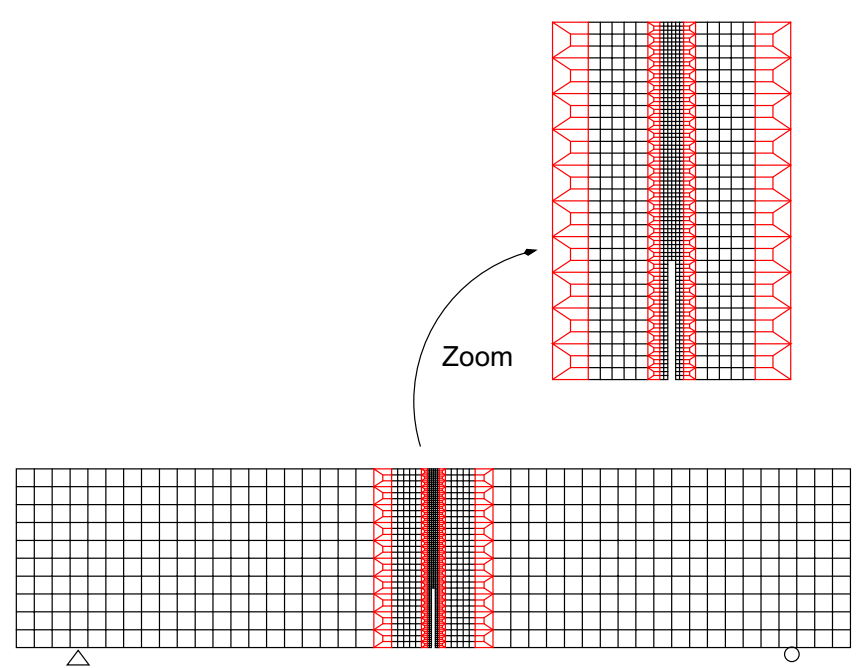

Fig. 5. The mesh of the beam

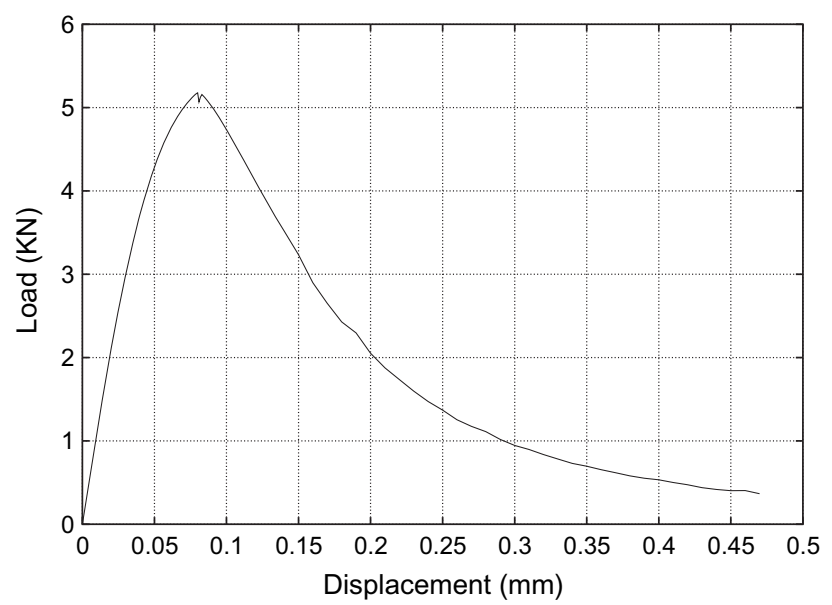

Fig. 6. The numerical load-displacement curve. 


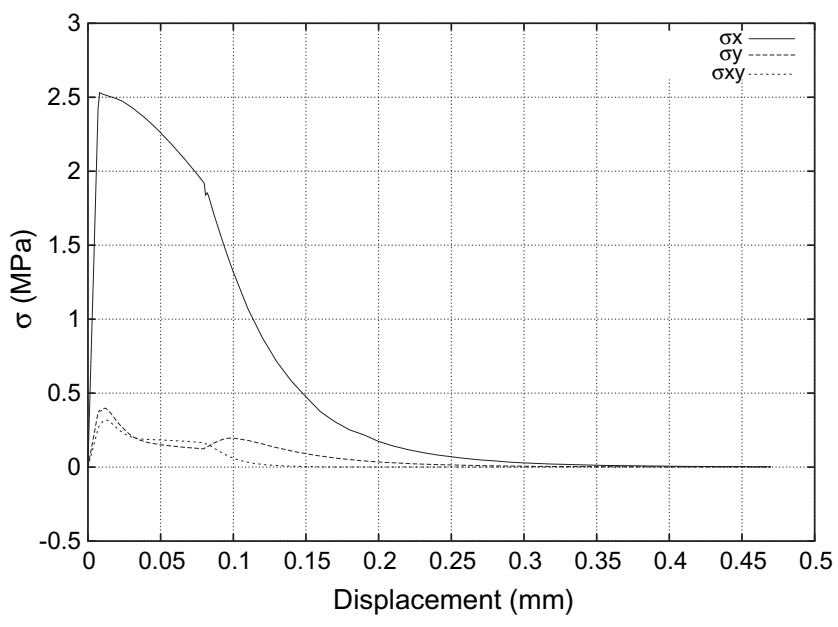

Fig. 7. Evolution of the stress tensor components: Cartesian components.

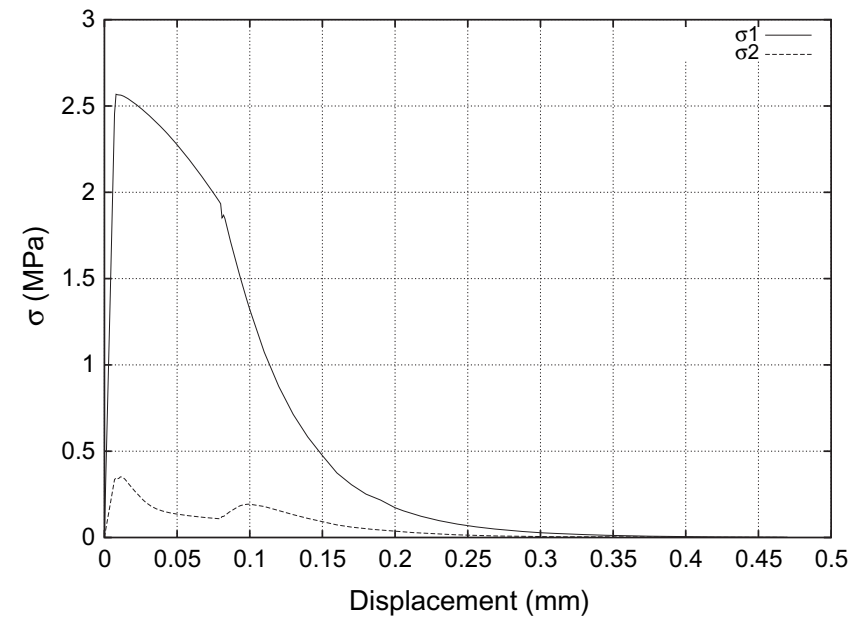

Fig. 8. Evolution of the stress tensor components: principal components.
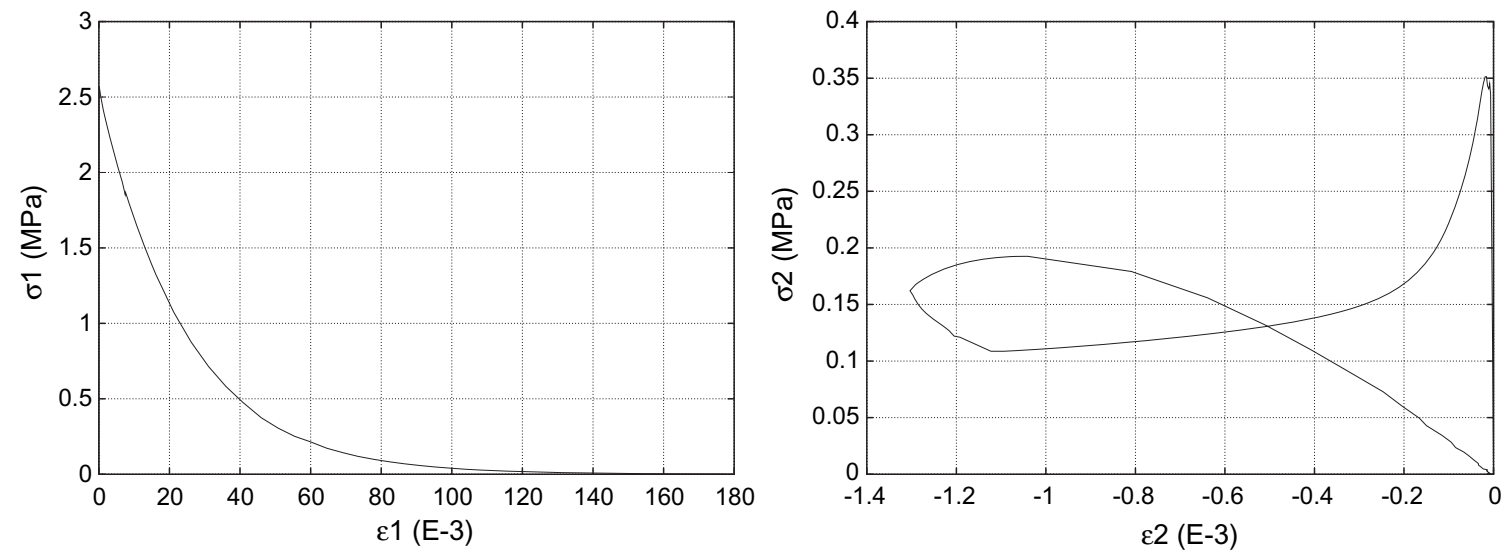

Fig. 9. Principal stresses vs. principal strains. 
using a Mazars equivalent strain (Eq. (9)), the presence of a positive minor principal stress increases the tensile strength (the peak of the major principal stress is about $2.56 \mathrm{MPa}>f_{t}$ ). The evolution of the biaxiality ratio $\sigma_{2} / \sigma_{1}$ shown in Fig. 10 reveals a biaxial tension state in the vicinity of the crack. This ratio varies within one element during loading. Along the crack, the biaxial stress ratio is different from a finite-element to another. In order to evaluate the dependence of the fracture energy as a function of the biaxiality ratio, an analytical expression (similar to that proposed in uniaxial tension, Eq. (16)) is proposed.

Let us denote $\gamma$ the biaxial stress ratio $\sigma_{2} / \sigma_{1}$. Firstly, for a biaxial-tension state with $0<\gamma<1$, the biaxial strain ratio is given by

$$
\frac{\sigma_{2}}{\sigma_{1}}=\frac{\tilde{\sigma}_{2}}{\tilde{\sigma}_{1}}=\gamma \Rightarrow \frac{\varepsilon_{2}}{\varepsilon_{1}}=\frac{\gamma-v}{1-\gamma v}
$$

For $0<\gamma<1$, the biaxial strain ratio is positive for $\gamma \geqslant 0.2$ and negative for $\gamma<0.2$. The Mazars equivalent strain (Eq. (9)) reads

$$
\begin{aligned}
& \gamma<0.2 \Rightarrow \tilde{\varepsilon}=\varepsilon_{1} \\
& \gamma \geqslant 0.2 \Rightarrow \tilde{\varepsilon}=\varepsilon_{1} \sqrt{\frac{(1-\gamma v)^{2}+(\gamma-v)^{2}}{(1-\gamma v)^{2}}}
\end{aligned}
$$

In terms of the effective stresses, the fracture energy is given by

$$
\frac{G_{f}}{h}=\int_{0}^{\infty}(1-d) \tilde{\sigma}_{1} d \varepsilon_{1}+\int_{0}^{\infty}(1-d) \tilde{\sigma}_{2} d \varepsilon_{2}
$$

We express all the stress and strain components as a function of $\varepsilon_{1}$. After computation, the fracture energy reads

$$
\begin{aligned}
& \gamma<0.2 \Rightarrow G_{f}=h \eta_{1} E\left(\frac{\varepsilon_{d 0}}{B}+\frac{\varepsilon_{d 0}^{2}}{2}\right) \\
& \gamma \geqslant 0.2 \Rightarrow G_{f}=h \eta_{2} E\left(\frac{\varepsilon_{d 0}}{B}+\frac{\varepsilon_{d 0}^{2}}{2}\right)
\end{aligned}
$$

with

$$
\left.\left.\eta_{1}=\frac{\left(1-2 \gamma v+\gamma^{2}\right)}{(1-\gamma v)^{2}}\right), \eta_{2}=\frac{\left(1-2 \gamma v+\gamma^{2}\right)}{(1-\gamma v)^{2}+(\gamma-v)^{2}}\right)
$$

Fig. 11 shows the evolution of the fracture energy as a function of the biaxial ratio. Eqs. (23) and (24) are only valid for biaxial tension $(0<\gamma<1)$. In the case of biaxial stress state with tension in one direction combined with compression in the other direction (i.e. for $\gamma<0$ ), finding an analytical solution for $G_{f}$ with the proposed damage model is not a trivial task. The situation is complicated by the fact that under compressive loading, the stress does not exhibit the same evolution as under tensile loading. For the negative biaxial stress ratio, the biaxial strain ratio is given by

$$
\gamma=\frac{\left(1-d^{\beta}\right) \tilde{\sigma}_{2}}{(1-d) \tilde{\sigma}_{1}} \Rightarrow \frac{\varepsilon_{2}}{\varepsilon_{1}}=\frac{\gamma(1-d)-v\left(1-d^{\beta}\right)}{\left(1-d^{\beta}\right)-\gamma v(1-d)}
$$

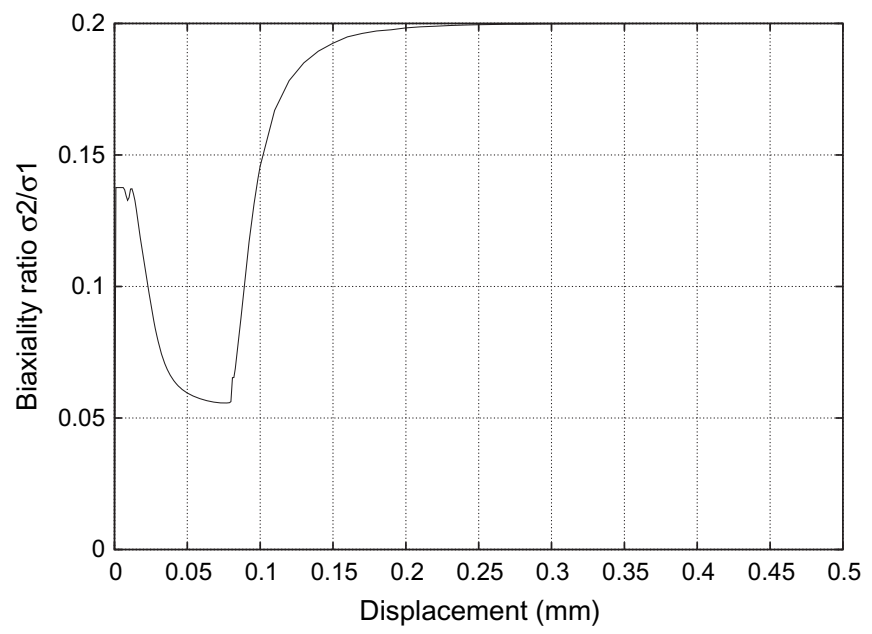

Fig. 10. Evolution of the principal stress biaxiality ratio. 


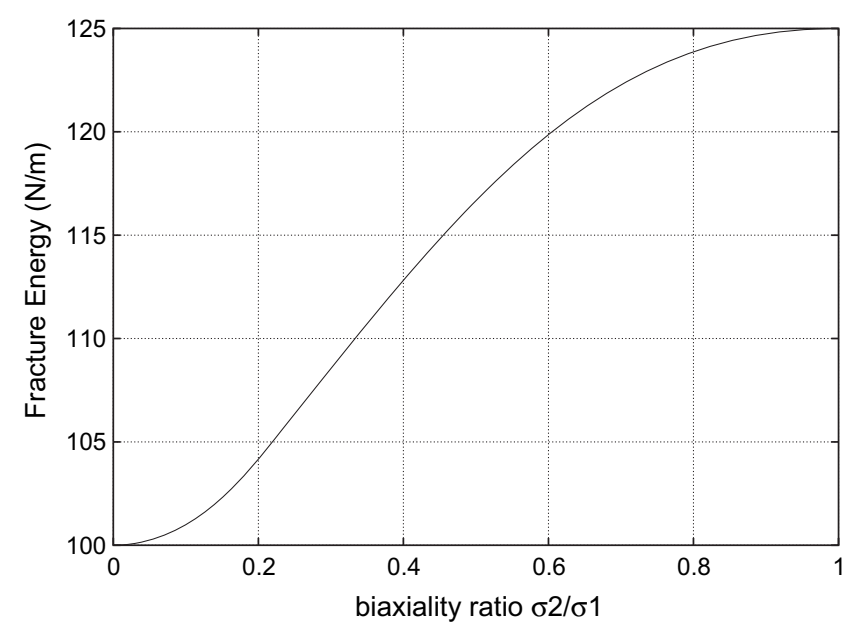

Fig. 11. Evolution of the fracture energy as a function of the biaxiality ratio.

Based on the forgoing analysis, it is clear that for a notched beam under three-point bending, the crack front exhibits biaxial stress state. However, the presence of the transversal stress (the stress perpendicular to the beam axis) has a small impact on the dissipated energy. For the damage-based model proposed above, the amount of the dissipated energy needed to initiate the crack is slightly different from that computed for uniaxial tension (used as an input parameter to perform the numerical simulation).

The fracture energy computed under biaxial stress state depends on the biaxiality ratio. This ratio is not constant during loading. It varies from one finite element to another. It also varies (during loading) within the same finite element.

\section{Inverse analysis procedure}

In order to find a trend for the development of the fracture energy with age, inverse analysis is carried out using the damage model proposed above. The softening curve is searched such that the fitted curve approximates the experimental one. The best material parameters set is therefore obtained. The fracture energy and the tensile strength are treated as fundamentals input material properties. The fracture energy is the area under the stress-displacement softening curve and it is assumed to be constant for all finite elements. It does not vary along the crack path. As it has been outlined in the introduction, a size/ligament effect on the specific fracture energy $G_{f}$ exists. According the local energy concept[10], to take into account the boundary effect, a bilinear distribution is assumed to represent the crack path variation of the fracture energy. Consequently, the application and the validity of our mechanical damage model is compromised in the boundary region. The model could only be valid in the inner zone limited by the transition length $a_{1}^{*}$ (see Fig. 1) where a size independent fracture energy could be estimated.

A transition length could be evaluated in order to fix the part of the P-CMOD experimental curve to be fitted. Using the bilinear model, if the RILEM's Fracture energy is given through the P- $\delta$ curves for specimens with different sizes, the transition length could be evaluated [10]. Also, the Acoustic Emission technique (AE) provides an excellent tool to estimate the local fracture energy distribution and consequently the transition length values [22]. In the present study, the P- $\delta$ curves obtained are unfortunately not exploitable. Also, AE technique has not been explored. Only the P-CMOD curves have been well established. Therefore, in order to approximate the size independent fracture energy, only a part of the P-CMOD curve has to be fitted when performing inverse analysis. The long tail of the P-CMOD curve after the peak-load is ignored. Two different values of CMOD $(\mathrm{CMOD}=0.2 \mathrm{~mm}$ and $\mathrm{CMOD}=0.1 \mathrm{~mm})$ are considered in order to study the influence of the cut-off value on the identified fracture energy.

\subsection{Inverse analysis algorithm}

To perform inverse analysis, the Levenberg-Marquardt Algorithm (LMA) is used [23-25]. Also known as the damped least-squares (DLS), it is one of the most important methods for solving systems of nonlinear equations. It is based on an iterative technique to locate the minimum of a multivariate functions expressed as the sum of squares of nonlinear real valued functions. It is widely adopted for solving curve-fitting problems in many research area [26-28]. To obtain the optimum solution of the experimental P-CMOD curve, the sum of weighted squares of the errors between the measured data $F\left(u_{i}\right)$ and the curve-fit function $F^{*}\left(u_{i}, p\right)$ is minimised (where $p$ is the vector of the damage model parameters $\left(p=f_{t}\right.$, $\left.G_{f}\right)$ ). 
Table 1

Characteristics of used aggregates.

\begin{tabular}{lll}
\hline & Sand $0 / 4$ & Gravel $4 / 20$ \\
\hline Water content & 3.5 & 2.1 \\
Absorption & 0.7 & 1.39 \\
Density & 2.6 & 2.57 \\
\hline
\end{tabular}

$$
\chi^{2}(p)=\frac{1}{2} \sum_{i=1}^{m}\left[\frac{F\left(u_{i}\right)-F^{*}\left(u_{i}, p\right)}{z_{i}}\right]^{2}
$$

this function is called the chi-squared error criterion, where $z$ indexes the error in measurement of $F\left(u_{i}\right)$. The inverse analysis procedure involves two major steps:

- Formulation of the mechanical model.

- Estimation of the coefficients of this model by using inverse analysis.

The LMA nonlinear equation is given by

$$
\left[J^{T} Z J+\lambda I\right] \alpha=J^{T} Z\left(F-F^{*}\right)
$$

where $J$ is the Jacobian matrix. $Z$ the weighted matrix (a diagonal matrix with $Z_{i i}=\frac{1}{Z_{i i}}$ ). In each iteration, the best perturbation $\alpha$ of the vector of parameters $p$ that reduces $\chi^{2}(p)$ is computed. The Jacobian matrix is numerically approximated using backward differences. The LMA is robust and efficient even if it starts far from the final minimum. However, there is no sense to force it starting with a far initial parameters set. In our study, the solution found at each age is used as input parameter in the following one.

\section{Experiment}

\subsection{Concrete formulation}

The experimental work is part of a French national project CEOS.fr [29]. The materials constituting the CEOS concrete [29] are: semi-crushed gravel of class $4 / 20 \mathrm{~mm}$, alluvial sand of class 0/4 mm and Cement CEMI 52.2 N (EN 197-1 and EN 197-2)

Table 2

Concrete formulation.

\begin{tabular}{ll}
\hline & Dosage $\left(\mathrm{kg} / \mathrm{m}^{3}\right)$ \\
\hline Gravel 4/20 & 980 \\
Sand 0/4 & 785 \\
CEMI 52.2 N & 400 \\
Super plasticizer & 1.8 \\
Added water & 154.1 \\
Effective water & 165.9 \\
\hline
\end{tabular}

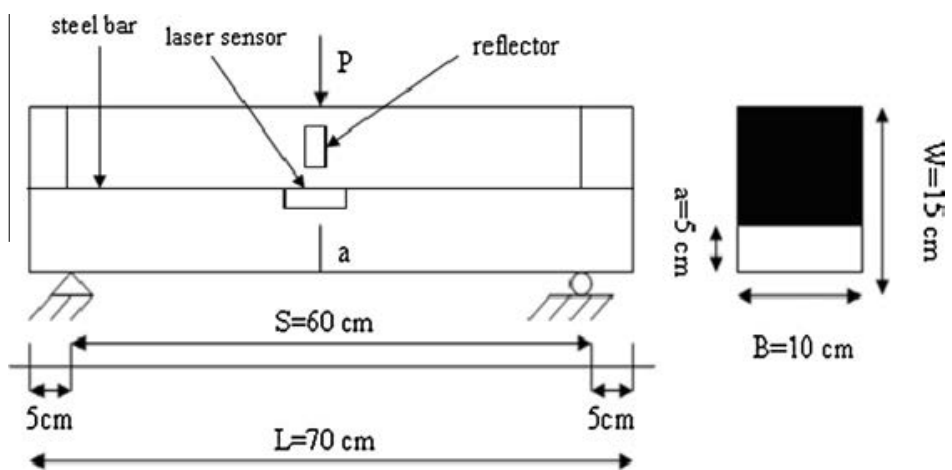

Fig. 12. Schematic representation of the three-point bending test setup. 
(see Table 1). A small amount of super-plasticizer (Optima 206) was adjusted manually for workability. The formulation used is given in Table 2. The water to cement ratio $(\mathrm{W} / \mathrm{C})$ is 0.42 and the gravel to sand ratio $(\mathrm{G} / \mathrm{S})$ is 1.25 .

\subsection{Experimental procedure}

Concrete was poured into moulds of dimensions $10 * 15 * 70 \mathrm{~cm}^{3}$ (Fig. 12). A Teflon plate with a thickness of about $3 \mathrm{~mm}$ was placed in the mould before casting for the notch position. It was removed at the time of the test. Also, two metallic plates

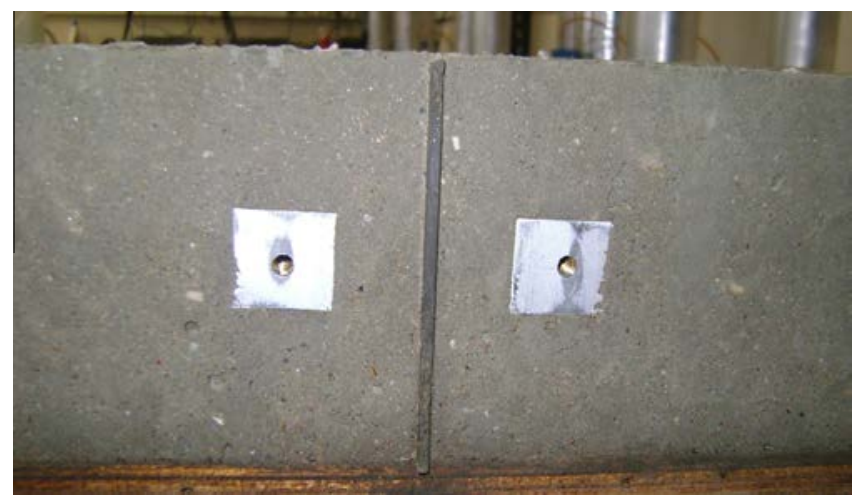

Fig. 13. Metallic plates placed in the mould.

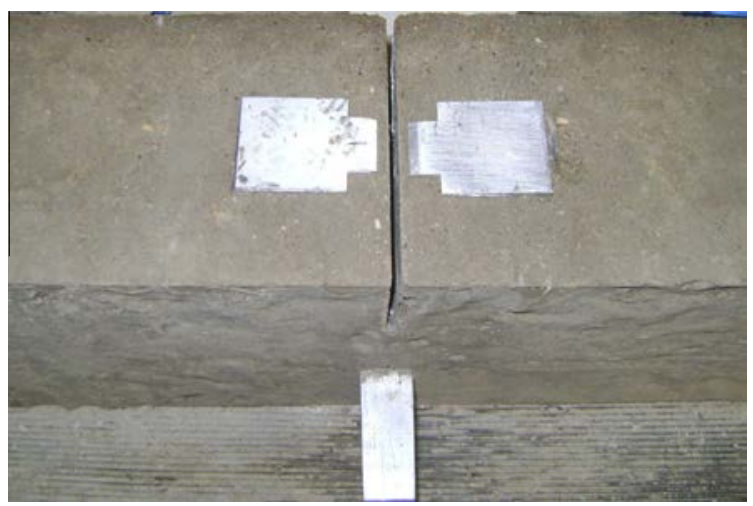

Fig. 14. Metallic plates used to fix the CMOD gauges.

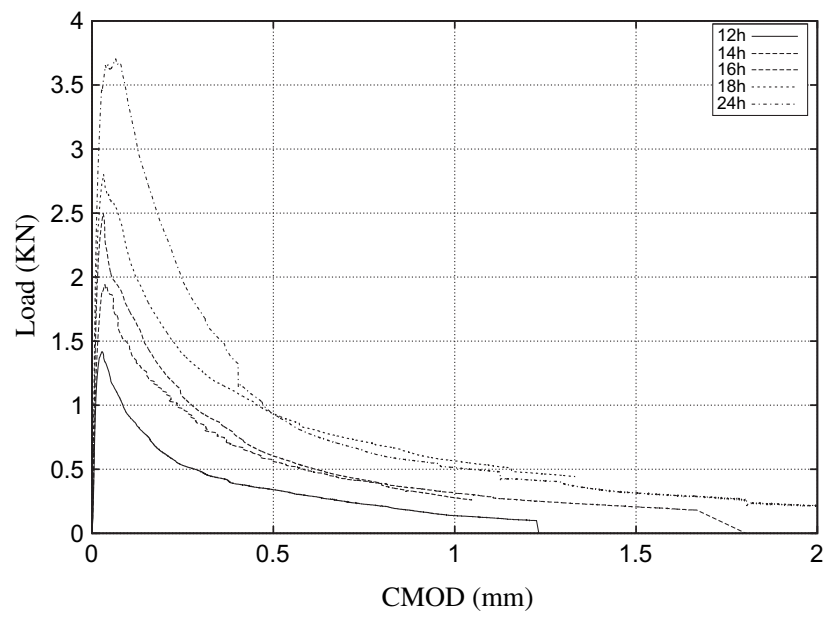

Fig. 15. Load-CMOD curves. 
were placed in the mould at the bottom of the beam on which two other metallic plates are fixed when the beam is demoulded (Fig. 13). These second plates were then used to fix the CMOD gauges (Fig. 14). To better interpret the repeatability tests, the slump test of the Abrams cone was carried out. Concrete was poured into moulds in two layers and vibrated with a plate vibrator. Specimens were then covered with an impermeable plastic sheet and kept in an air conditioned room at a

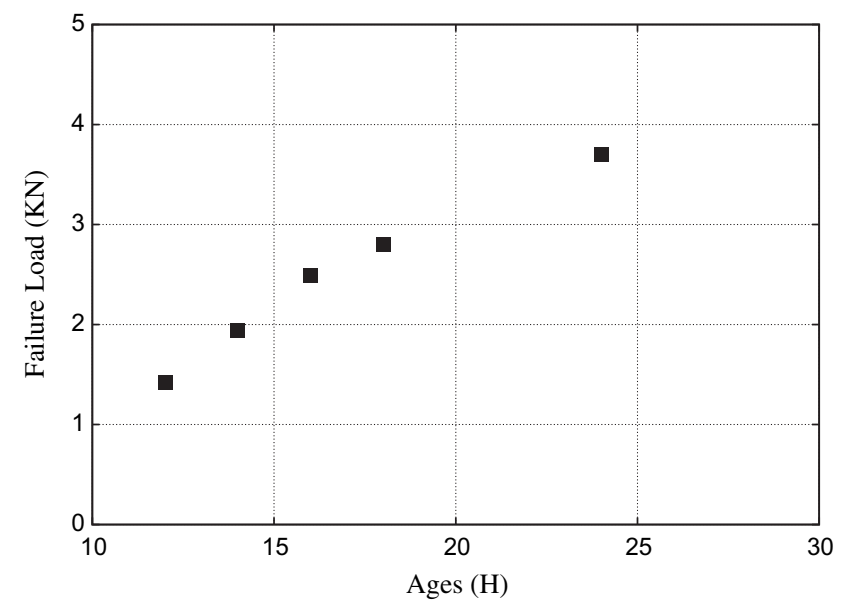

Fig. 16. Failure load evolution

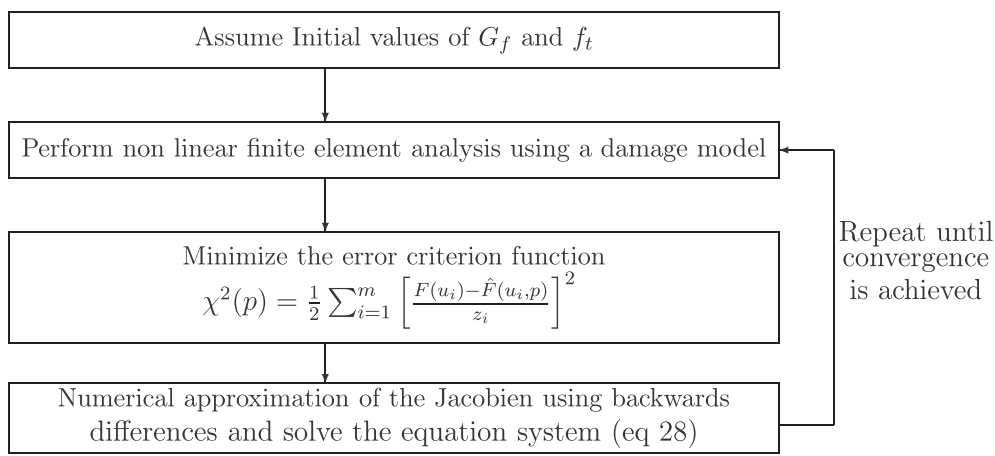

Fig. 17. The numerical procedure.

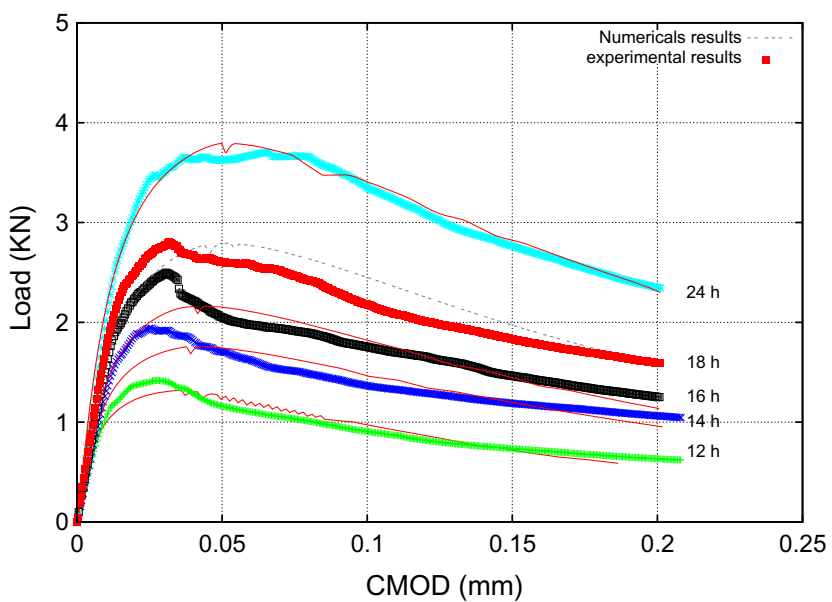

Fig. 18. Comparison between fitted and experimental P-CMOD curves. 
temperature of $20 \mathrm{C}$ and a relative humidity of $50 \%$. The formwork was removed with care one hour before the test to glue the plates (which were used to hold the CMOD gauge) and the reflector for the measurement of the deflection.

The loading frame consists of an Instron make closed loop universal testing machine of $160 \mathrm{kN}$ capacity. The load was applied with a circular jack to ensure a point load. A rubber pad was placed between the load jack and the beam to take care of the surface unevenness and to avoid damage under the load. The beam was simply supported on two circular supports. The notch mouth opening displacement was measured with a CMOD gauge. The two blades of the CMOD gauge, each $10 \mathrm{~mm}$ in length, were attached to two metallic plates $10 \mathrm{~mm}$ apart, one on either side of the notch at the bottom face of the beam. These metal plates were firmly attached to other plates (which were inserted into the mould before casting concrete) with high strength glue that ensures perfect stability of plates. All the tests were performed under crack mouth opening displacement control with a slow rate of $0.5 \mu \mathrm{m} / \mathrm{s}$. This allowed to reach the peak load in about one minute. Through these tests, the load was obtained as a function of time, CMOD and deflection. However, the load-deflection curve is not always reliable compared to the load-CMOD which is in most case good. The data were recorded every one second.

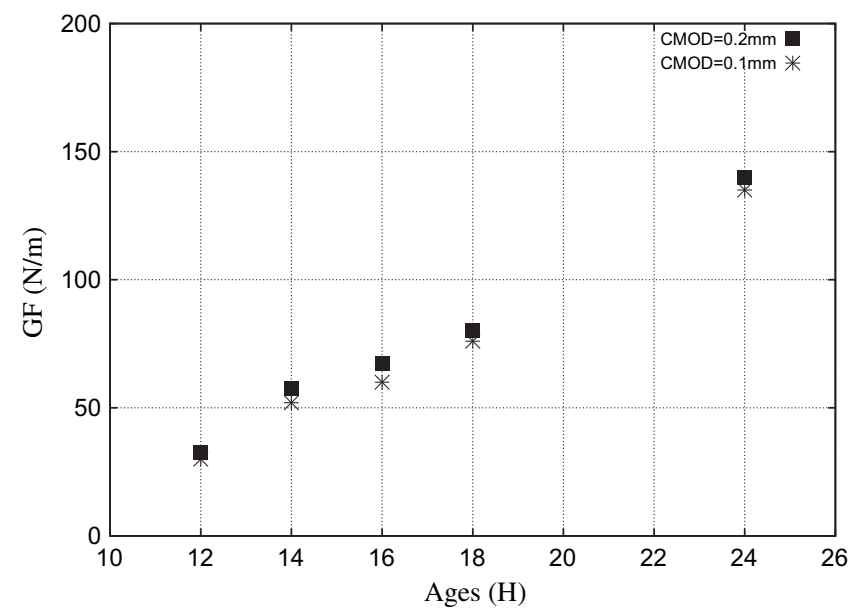

Fig. 19. Evolution of the size independent fracture energy with age (for CMOD $=0.2 \mathrm{~mm}$ and $\mathrm{CMOD}=0.1 \mathrm{~mm}$ ).

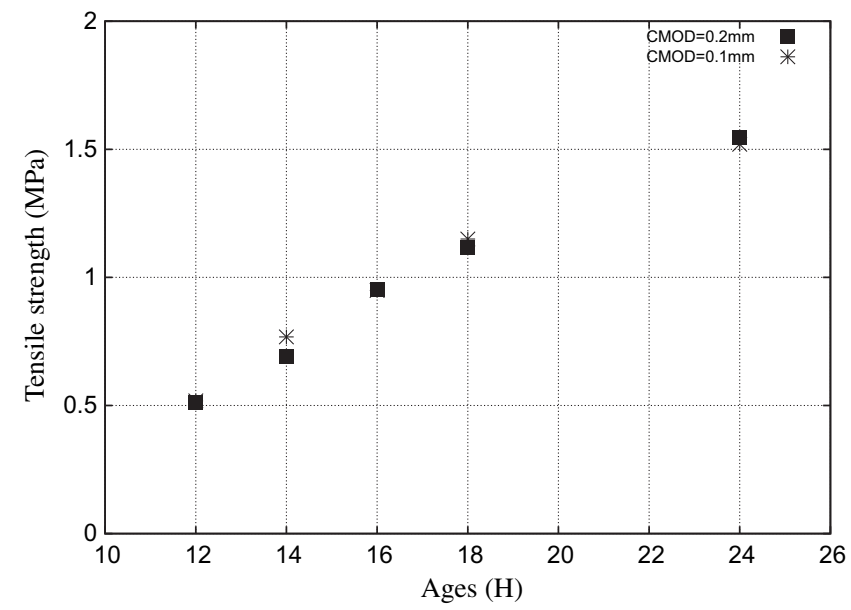

Fig. 20. Evolution of the tensile strength with age (for $C M O D=0.2 \mathrm{~mm}$ and $\mathrm{CMOD}=0.1 \mathrm{~mm}$ ).

Table 3

comparison of the fracture energy dissipated by the model and the identified fracture energy.

\begin{tabular}{lllll}
\hline Age & $24 \mathrm{~h}$ & $18 \mathrm{~h}$ & $16 \mathrm{~h}$ & $14 \mathrm{~h}$ \\
\hline$G_{F}^{\text {uniaxial }}($ identified $)(\mathrm{N} / \mathrm{m})$ & 139.73 & 80 & 67.42 & 57.62 \\
$h *\left(\int_{0}^{\infty} \sigma_{1} d \varepsilon_{1}+\int_{0}^{\infty} \sigma_{2} d \varepsilon_{2}\right)(\mathrm{N} / \mathrm{m})$ & 142.49 & 81.49 & 69.16 & 33.10 \\
\hline
\end{tabular}




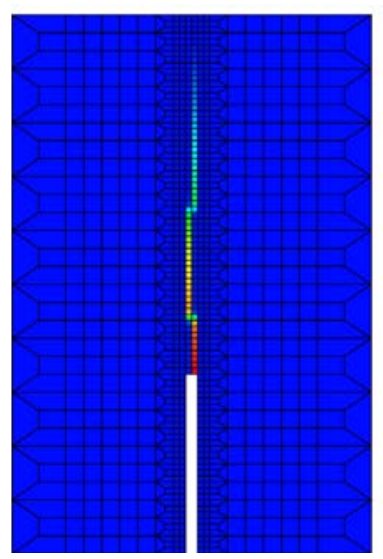

$1.44 \mathrm{E}-04$

1. $37 \mathrm{E}-04$

1. $30 \mathrm{E}-04$

$1.24 \mathrm{E}-04$

$1.17 \mathrm{E}-04$

$1.10 \mathrm{E}-04$

$1.03 \mathrm{E}-04$

9. $58 \mathrm{E}-05$

8. $89 \mathrm{E}-05$

8. $20 \mathrm{E}-05$

7. $50 \mathrm{E}-05$

6. $81 \mathrm{E}-05$

$6.12=05$

$5.43 \mathrm{E}-05$

4. $73 \mathrm{E}-05$

$4.04 \mathrm{E}-05$

3. $35 \mathrm{E}-05$

2. $65 \mathrm{E}-05$

1. $96 \mathrm{E}-05$

1. $27 \mathrm{E}-05$

$5.76 \mathrm{E}-06$

$14 \mathrm{H}$

$$
\begin{array}{r}
>-1.55 \mathrm{E}-08 \\
<1.45 \mathrm{E}-04 \\
1.44 \mathrm{E}-04 \\
1.37 \mathrm{E}-04 \\
1.30 \mathrm{E}-04 \\
1.23 \mathrm{E}-04 \\
1.17 \mathrm{E}-04 \\
1.10 \mathrm{E}-04 \\
1.03 \mathrm{E}-04 \\
9.58 \mathrm{E}-05 \\
8.89 \mathrm{E}-05 \\
8.19 \mathrm{E}-05 \\
7.50 \mathrm{E}-05 \\
6.81 \mathrm{E}-05 \\
6.12 \mathrm{E}-05 \\
5.42 \mathrm{E}-05 \\
4.73 \mathrm{E}-05 \\
4.04 \mathrm{E}-05 \\
3.35 \mathrm{E}-05 \\
2.65 \mathrm{E}-05 \\
1.96 \mathrm{E}-05 \\
1.27 \mathrm{E}-05 \\
5.76 \mathrm{E}-06
\end{array}
$$

$16 \mathrm{H}$

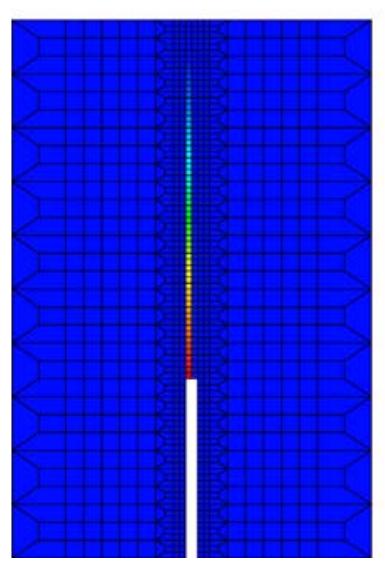

$18 \mathrm{H}$

$>-1.50 \mathrm{E}-08$

$1.42 \mathrm{E}-04$

1. $35 \mathrm{E}-04$

1. $29 \mathrm{E}-04$

1. $22 \mathrm{E}-04$

1. $15 \mathrm{E}-04$

$1.08 \mathrm{E}-04$

1. $01 \mathrm{E}-04$

9. $45 \mathrm{E}-05$

8. $77 \mathrm{E}-05$

8. $08 \mathrm{E}-05$

$7.40 \mathrm{E}-05$

6. $72 \mathrm{E}-05$

$6.03 \mathrm{E}-05$

5. $35 \mathrm{E}-05$

$4.67 \mathrm{E}-05$

3. $98 \mathrm{E}-05$

3. $30 \mathrm{E}-05$

2. $62 \mathrm{E}-05$

1. $93 \mathrm{E}-05$

1.25E-05

. $25 \mathrm{E}-05$

$5.68 \mathrm{E}-06$

$>-3.08 \mathrm{E}-10$

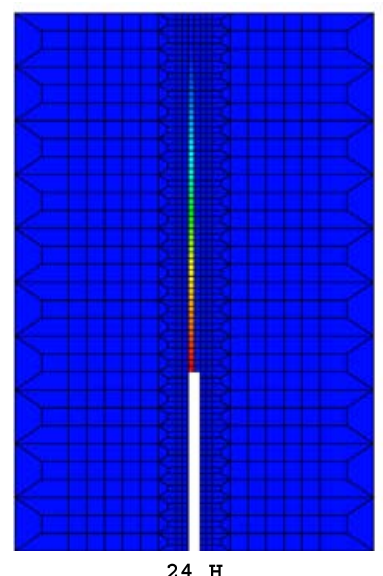

$1.37 \mathrm{E}-04$

1. $30 \mathrm{E}-04$

$1.24 \mathrm{E}-04$

$1.11 \mathrm{E}-04$

$1.04 \mathrm{E}-04$

$9.74 \mathrm{E}-05$

$9.08 \mathrm{E}-05$

8. $43 \mathrm{E}-05$

$7.77 \mathrm{E}-05$

$7.11 \mathrm{E}-05$

$6.46 \mathrm{E}-05$

$5.80 \mathrm{E}-05$

$5.14 \mathrm{E}-05$

$4.49 \mathrm{E}-05$

3. $83 \mathrm{E}-05$

$3.17 \mathrm{E}-05$

2. $52 \mathrm{E}-05$

$1.86 \mathrm{E}-05$

1. $20 \mathrm{E}-05$

$5.47 \mathrm{E}-06$

$24 \mathrm{H}$

Fig. 21. The crack opening fields at different ages $(\delta(m))$. 


\subsection{Experimental results and discussion}

The main objective of this work is the determination of the fracture energy. The P-CMOD curves are analysed carefully. The results for the concrete aged less than 24 h have a special interest because very few data are available in the literature. The graph of Fig. 15 shows that the failure load and the slope of the elastic part increase with age while the post-peak part decrease rapidly. The increase of the failure load and elastic slope shows that the fracture properties of concrete increased with age. The increase in the elastic slope can be attributed to the evolution of the Young's modulus with time.

Fig. 16 represents the failure vs time, and gives an idea on the evolution of concrete strength. At early age this load is low, and then it increased significantly. At the age of $24 \mathrm{~h}$, it reached $3.7 \mathrm{KN}$, which is a significant value regarding those obtained for a mature concrete. This can be explained by the fact that from 24 h the hydration phenomenon reached advanced stages, the solid skeleton is formed and cohesion between the different components becomes stronger.

\section{Numerical results and discussions}

The procedure explained in Fig. 17 is performed using the finite element code Cast3M [30]. The mesh of the beam is represented in Fig. 5. The finite element configuration considered in Section 2.3 is adopted here. The inverse analysis procedure is performed using the fracture energy formula obtained under uniaxial tension (Eq. (16)).

Fig. 18 shows the comparison between the experimental results and the fitted ones. Overall, the numerical results are in good agreement with the experimental ones. The best fitted parameter set is obtained for the age of $24 \mathrm{~h}$. At very early age (before $24 \mathrm{~h}$ ), the material seems to exhibit a nonlinear behaviour up to the peak load. This is a natural observation since this nonlinear hardening is caused by the local softening behaviour. However, this nonlinearity is "very pronounced" up to the peak. For the damage model used in this paper, the local behaviour is elastic-linear up to the peak which may not be the case at very early ages where the material seems to exhibit both viscous and elastic behaviour. This might explain why the fitted numerical results stray a bit from the experimental ones in this region.

Fig. 19 shows the evolution of the size independent fracture energy for two different "cut-off" values. Similar results are obtained. Any other value that keeps the crack far from the boundary would give similar results. In the literature, a little research dealing with concrete at very early ages (before $24 \mathrm{~h}$ ) can be found. In [2], an upward trend was found regarding the evolution of the fracture energy at very early ages.

As it has been outlined in the introduction, the damage model used to perform inverse analysis is not able to capture the boundary effect as the fracture energy is assumed to be constant over the element size. The solution proposed was to fit only a portion of the P-CMOD curves. Hence, an estimation of the size independent fracture energy is obtained. Fig. 19 shows the development of the size independent fracture energy with age. Overall, the data indicate an "upward trend" which is in agreement with the experimental results. In Fig. 20, the evolution of the tensile strength is illustrated. As for the fracture energy, an increasing trend is observed.

In Table 3, the energy dissipated by the model (for the first cracked element situated in front of the notch with $h=1.6 \mathrm{e}-3 \mathrm{~m}$ ) is compared to the fracture energy identified from the inverse analysis procedure (for the first cut-off value $\mathrm{CMOD}=0.2 \mathrm{~mm}$ ). For each age, a slight difference exists between the two values.

According to the local energy concept, the size independent fracture energy could be estimated in the inner zone before the crack reaches the back boundary. In Fig. 21, the crack opening fields are illustrated for different ages. The crack opening computation was performed using the post-processing method developed by Matallah et al. [31,20] which allows to calculate crack openings from a nonlinear damage or plasticity model. For all beams, the crack patterns show that, at the displacement limit fixed to perform inverse analysis, the crack does not reach the boundary limit and the fracture process is not strongly disturbed by the boundary effects.

\section{Conclusions}

In this study, the fracture characteristics of concrete at very early ages are investigated. An experimental procedure was carried out to perform three point bending tests on notched beams of concrete specimens at ages before $24 \mathrm{~h}$. The P-CMOD curves obtained indicate an increasing trend of the evolution of the failure load and the post-peak softening which give a global indication of the concrete behaviour at very early age. In order to investigate the evolution of the fracture concrete characteristics, an inverse analysis procedure based on a softening damage model and a nonlinear inverse analysis algorithm has been developed. Two physical fractures characteristics has been used as input parameters: the tensile strength and the fracture energy. Overall, numerical results indicate an "upward trend" regarding the evolution of the fractures characteristics. As the damage model used to perform inverse analysis assumes a constant $\sigma-\delta$ relation across the crack length, only a portion of the P-CMOD curves has been used in fitting and a good estimation of the size independent fracture energy has been obtained according to the bilinear model [10]. However, regarding this point, further investigation should be considered. Indeed, experimentally, AE technique shows that the number of events increases with increase in distance from the notch tip before stabilize over a certain distance [22]. Hence, a tri-linear local fracture energy distribution should be considered. This implies that in the damage softening model the fracture energy is no longer constant. This aspect will be addressed in a future paper where acoustic emission technique will be used to obtain the form of the local fracture energy distribution. 


\section{References}

[1] Wittmann FH, Roelfstra PE, Mihashi H, Huang Y-Y, Zhang X-H, Nomura N, et al. Water-cement ratio and rate of loading on fracture energy of concrete. Mater Struct 1987;20:103-10.

[2] Østergaard L, Lange D, Stang H. Early age stress-crack opening relationships for high performance concrete. Cement Concr Comput 2004;26:563-72.

[3] De Schutter G, Taerwe L. Fracture energy of concrete at early ages. Mater Struct 1997;30:67-71.

[4] Kim J-K, Lee Y, Yi S-T. Fracture characteristics of concrete at early ages. Cement Concr Res 2004;34:507-19.

[5] Grondin F, Mounanga P, Roziére E, Loukili A, Mounia F, Regoin J, et al. Improving the characterization of early age cracking of concrete: engineering issues and scientific answers. CONCRACK 3 - RILEM-JCI international workshop on crack control of mass concrete and related issues concerning earlyage of concrete structures. Paris, March 15-16; 2012.

[6] Hillerborg A, Modéer M, Petersson P-E. Analysis of crack formation and crack growth in concrete by means of fracture mechanics and finite elements. Cement Concr Res 1976;6:773-81.

[7] Kwon S, Zhao Z, Shah S. Effect of specimen size on fracture energy and softening curve of concrete: Part ii. Inverse analysis and softening curve. Cement Concr Res 2008;38(8-9):1061-9.

[8] Bretschneider N, Slowik V, Villmann B, Mechtcherine V. Boundary effect on the softening curve of concrete. Engng Fract Mech 2011;78:2896-906.

[9] Baz ant ZP, Kazemi M. Size dependence of concrete fracture energy determined by rilem work-of-fracture method. Int J Fract 1991;51:121-38.

[10] Duan K, Hu XZ, Wittmann FH. Size effect on specific fracture energy of concrete. Engng Fract Mech 2007;74:87-96.

[11] Nallathambi P, Karihaloo BL, Heaton B. Effect of specimen and crack sizes, water/cement ration and coarse aggregate texture upon fracture toughness of concrete. Mag Concr Res 1984;36:227-36.

[12] Duan K, Hu XZ, Wittmann FH. Boundary effect on concrete fracture and non-constant fracture energy distribution. Engng Fract Mech 2003;70:2257-68.

[13] Hu XZ, Duan K, Wittmann F. Size effect: influence of proximity of fracture process zone to specimens boundary. Engng Fract Mech 2007;74:1093-100.

[14] $\mathrm{Hu} X-Z$, Wittmann F. Fracture energy and fracture process zone. Mater Struct 1992;25:319-26.

[15] Duan K, Hu XZ, Wittmann FH. Explanation of size effect in concrete fracture using non-uniform energy distribution. Mater Struct 2002;35:326-31.

[16] Bazant ZP, Oh B. Crack band theory for fracture of concrete. Mater Struct 1983;16:155-77.

[17] Fichant S, Pijaudier-Cabot G, La Borderie C. Continuum damage modelling: approximation of crack induced anisotropy. Mech Res Commun 1997;24:109-14.

[18] Fichant S, La Borderie C, Pijaudier-Cabot G. Isotropic and anisotropic description of damage in concrete structures. Mech Cohes Frict Mater 1999;4:339-59.

[19] La Borderie C. Stratégies et modèles de calculs pour les structures en béton. Habilitation à diriger des recherches (hdr), Université de Pau et des Pays de l'Adour, France; 2003.

[20] Matallah M, La Borderie C, Maurel O. A practical method to estimate crack openings in concrete structures. Int J Numer Anal Met 2010;34:1615-33.

[21] Jirásek M, Bauer M. Numerical aspects of the crack band approach. Comput Struct 2012;110-111:60-78.

[22] Muralidhara S, Raghu Prasad B, Karihaloo B, Singh R. Size-independent fracture energy in plain concrete beams using tri-linear model. Constr Build Mater 2011;25:3051-8.

[23] Levenberg K. A method for the solution of certain non-linear problems in least squares. Q Appl Math 1994;2:164-8.

[24] Marquardt D. An algorithm for least-squares estimation of nonlinear parameters. J Soc Ind Appl Math 1963;11:431-41.

[25] Nocedal J, Wright S. Numerical minimization. New York: Springer; 1999.

[26] Boadu FK. Handbook of geophysical exploration: seismic exploration, vol. 30. Pergamon; 2011 [Chapter 11: Permeability estimation with an RBF network and Levenberg-Marquardt learning].

[27] Yi S-T, Kim M-S, Kim J-K, Kim J-HJ. Effect of specimen size on flexural compressive strength of reinforced concrete members. Cement Concr Comput $2007 ; 23: 230-40$.

[28] Kleefeld A, Reißel M. The Levenberg-Marquardt method applied to a parameter estimation problem arising from electrical resistivity tomography. Appl Math Comput 2011;217:4490-501.

[29] Benchmark CEOS.fr:Comportement et évaluation des ouvrages spéciaux fissuration retrait. Réseau Génie Civil et Urbain, France; 2008.

[30] Verpaux P, Charras T, Millard A. Une approche moderne du calcul des structures. In calculs des structures et intelligence artificielle, Pluralis, Paris; 1988.

[31] Matallah M, La Borderie C. Inelasticity-damage-based model to numerical modelling of concrete cracking. Engng Fract Mech 2009;76:1087-108. 